\title{
One in a million, or one in thousand: What is the morbidity of rabies in India?
}

\author{
Janie M. Baxter
}

Centre for Population Health Sciences, University of Edinburgh, Edinburgh, Scotland, UK

$\mathrm{R}$ abies is the $10^{\text {th }}$ biggest cause of death due to infectious diseases worldwide [1]. It is estimated that 2.5 billion people across 100 countries are at risk of contracting rabies [1]. The annual death toll is around 50000-60000, with 99\% occurring in tropical developing countries [1]. Around $36 \%$ of these rabies related deaths occur in India every year with dog bites being responsible for $95-97 \%$ of these cases [2,3]. The annual estimated number of dog bites in India is 17.4 million, leading to estimated 18000 20000 cases of human ra-
Rabies is the 10th biggest cause of death due to infectious diseases worldwide. The an- nual death toll is around 50000-60000, with 99\% occurring in tropical developing coun- tries. Based on available evidence, a fair es- timate of rabies burden in India is 2.74 ra- bies cases per 100000 people annually.

timates of rabies burden in India, which makes it difficult for policy makers to understand the scale of the problem and plan how to tackle it. As rabies is an acute condition and its control is centered on preventive measures, incidence is the most appropriate measure of its burden in the context of improving health policy.

Over the past decade, I could only identify six studies that seemed to report the incidence of rabies in different parts of India [8-13]. I use them here to try to discuss what would be a reasonable estimate based on bies per year [4]. Rabies is a fatal condition with no cure, but there are preventive interventions to reduce its burden, although they are not well adopted in India. As a result, India has the largest contribution to worldwide rabies mortality [5-7]. Across Asia the annual expenditure due to rabies is estimated to be reaching 563 million USD [3].

Rabies typically affects the most vulnerable members of society, children and lower socio-economic classes [3]. This is likely due to poor knowledge and uptake of preventive measures. Studies have shown only around $70 \%$ of the population of India have heard of rabies, only around 30\% knew to wash wounds after animal bites and a large proportion were not compliant with treatment [5]. Furthermore, rabies is not a notifiable disease in India, which makes it probable that the true burden has been underestimated [7]. Although there have been reviews focusing on rabies burden in India, the majority were published prior to 2000. They all pointed to large discrepancy between es- their reported results, but perhaps equally importantly, to expose the challenges of understanding and assessing rabies morbidity in a low-resource setting. Table 1 shows that the case definitions used in each study were poorly reported across the board. It is also worth noting that some studies estimated the incidence of animal bites as a proxy for rabies incidence, as the latter data was not known. In order to compare estimates of rabies incidence across the 6 included studies it was necessary to first standardise all of the results. As two of the studies already reported rabies incidence as the annual number of cases per 100000 of population, I decided to standardise all of the results to these units. All studies results were reported per year.

There was an incredible variation in the standardised measure of incidence across the studies. Table 1 shows the standardized estimates for each study, ranging from 0.05 to 1700 rabies cases per 100000 population. If the sample size is taken into account, then the weighted mean calcu- 
Table 1 Case definitions used in studies of rabies in India in the past decade

\begin{tabular}{|c|c|c|}
\hline StUdY TITLE & CASE DEFINITIONS & $\begin{array}{l}\text { STANDARDIZED ESTIMATE OF ANNUAL RABIES } \\
\text { INCIDENCE AND UNITS }\end{array}$ \\
\hline $\begin{array}{l}\text { Assessing the burden of human rabies in India: results } \\
\text { of a national multi-center epidemiological survey [8] }\end{array}$ & $\begin{array}{l}\text { Case definition not given. Rabies diagnosis from the } \\
\text { records of } 22 \text { infectious diseases hospitals from all } \\
\text { regions of the country for 1992-2002. }\end{array}$ & 2 per 100000 population \\
\hline $\begin{array}{l}\text { Re-evaluating the burden of rabies in Africa and Asia } \\
\text { [9] }\end{array}$ & Case definition not given. & 130 per 100000 population \\
\hline $\begin{array}{l}\text { An epidemiological study of animal bites in India: } \\
\text { results of a WHO sponsored national multi-centric } \\
\text { rabies survey [10] }\end{array}$ & $\begin{array}{l}\text { Animal bite reported in the previous year in each } \\
\text { household surveyed. Report based on memory recall of } \\
\text { reliable, responsible adult or available home records. }\end{array}$ & 1700 per 100000 population \\
\hline $\begin{array}{l}\text { A survey of hospitals managing human rabies cases } \\
\text { in India [11] }\end{array}$ & $\begin{array}{l}\text { Case definition not given. Cases were identified from } \\
\text { medical records across } 23 \text { medical centers. }\end{array}$ & 0.05 per 100000 population \\
\hline Human Rabies in Delhi [12] & $\begin{array}{l}\text { Rabies diagnosis was made on the basis of exposure } \\
\text { history and presenting clinical features. }\end{array}$ & 0.88 per 100000 population \\
\hline $\begin{array}{l}\text { Epidemiology of human rabies cases in Kolkata with } \\
\text { its application to post prophylaxis [13] }\end{array}$ & $\begin{array}{l}\text { Case definition not given. Rabies cases identify at Kol- } \\
\text { kata's single referral center. }\end{array}$ & 3.48 per 100000 population \\
\hline
\end{tabular}

lated for the 6 studies was 128.74 per 100000 , but it was mainly affected by the 2 largest estimates of rabies incidence, as these had the second and third largest sample sizes. The simple median is 2.74 per 100000 . Unsurprisingly, the 2 most extreme values were produced from the studies that estimated the incidence of animal bites as a proxy, and did not measure the incidence of human rabies directly. As a result, those two studies are likely to greatly over estimate the incidence of rabies. If those two studies are ignored, then the mean number of annual rabies cases from the remaining 4 studies is 1.6 per 100000 and the weighted mean is 2 per 100000 .

I propose that the median of 2.74 rabies cases per 100000 people annually may be a fair estimate of rabies burden from the available evidence. All of the studies were retrospective cohort studies, with the exception of one prospective cohort, which is a relatively robust study design. They were all also conducted over at least a 1 -year period and therefore provide a reliable estimate of annual incidence. 3 of the 6 studies contained very large study populations, including one study that contained population-wide data, leading to increased precision of the estimate. Four of the studies aimed to estimate the incidence of rabies across India and as such they used multi-centered approach across various regions. However, two of the studies focused the populations of single areas of Delhi and Kolkata, which are not likely to be demographically sim-

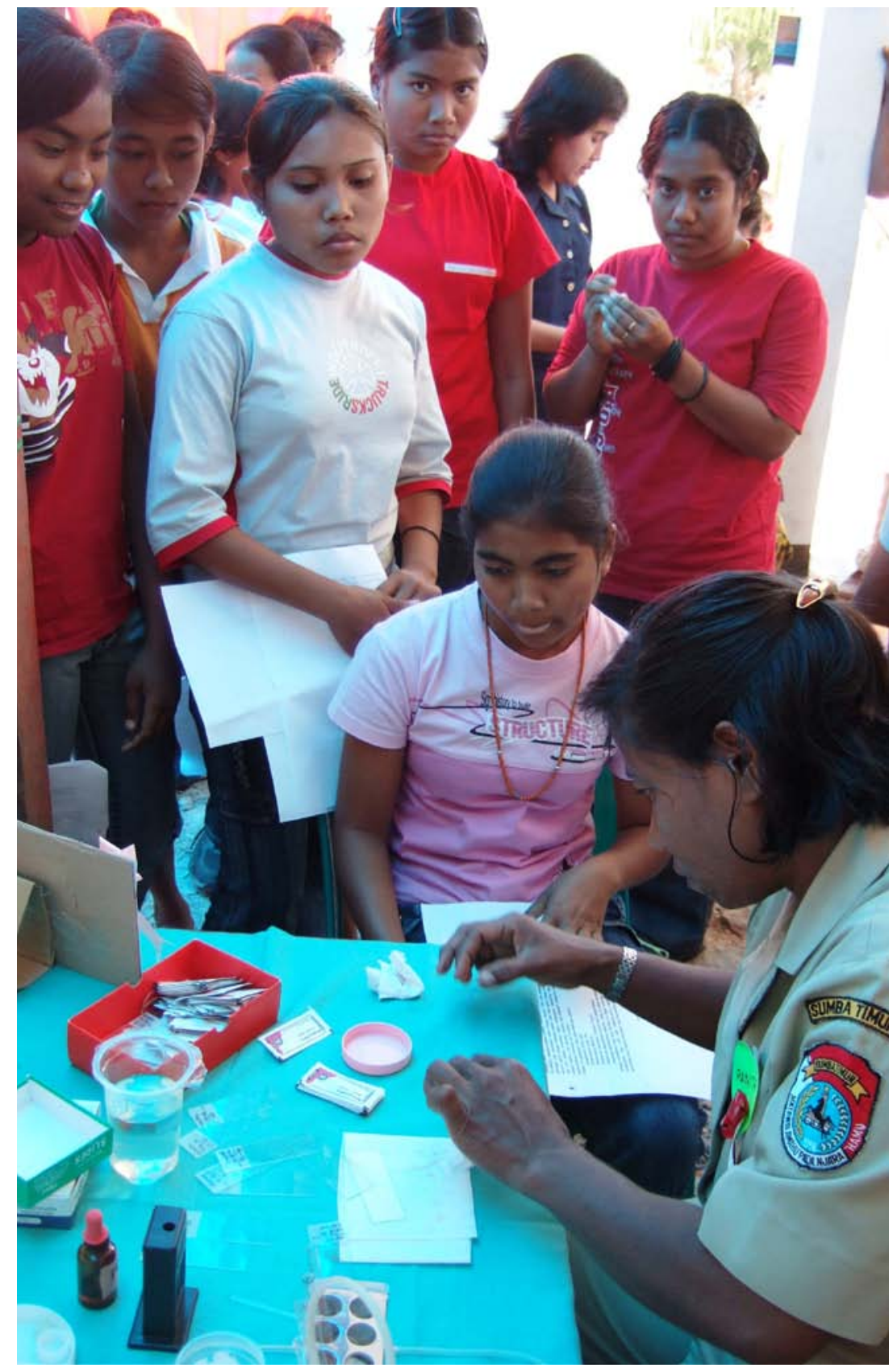

Photo: Courtesy of Dr David Hipgrave, personal collection 
ilar or at similar risk of rabies as the Indian population as a whole. All but one of the studies recruited participants from hospitals, this biases the study as only the incidence of those attending hospital can be calculated. This may exclude those with poorer education, access to health care or those who seek traditional healing who may also be more likely to be exposed to rabies. Across all 6 studies there was potential for error and bias in the measurement of incidence particularly as none of the studies outlined strict case definitions to ensure cases of rabies were correctly identified. Also the reporting of rabies in India is known to be poor and it is likely that many cases went unreported during the study period [7]. The influence of chance was not well addressed in any of the studies with no P-values or confidence intervals reported for any of the analyses preformed. An additional source of potential bias is that 3 or the 6 identified studies were published by the same author.

Clearly, further research will be required in order to produce a better estimate of the incidence of rabies in India. This could be facilitated by making rabies a notifiable disease in order to have population-wide data of confirmed cases [14-16]. As the disease is incurable, it is important to focus policy and planning on reducing the incidence of exposure to rabies and promoting awareness and behaviors which can help to prevent the disease. It would be necessary to consult demographics of rabies exposure and barriers to treatment to best inform these changes [17]. For example vulnerable populations should be targeted. This includes those of lower socio-economic class, living in ru-
Further research will be required in order to produce a better estimate of the incidence of rabies in India. This could be facilitated by making rabies a notifiable disease in order to have population-wide data of confirmed cases. As the disease is incurable, it is important to focus policy and planning on reducing the incidence of exposure to rabies and promoting awareness and behaviors which can help to prevent the disease.

ral areas, living in areas of high human:dog density and children $[18,19]$. Considering some of the barriers to treatment outlined in the introduction, education is one important way of reducing rabies incidence [5]. This could include educating people about the contraction of rabies, underlining the importance of seeking treatment, advising washing animal bites with soap and water and avoiding the application of harmful traditional remedies. There is also evidence that further education is needed among doctors [20]. Other important areas to be tackled by policy are the control and vaccination of India's burgeoning dog population and encouraging the use of cell culture vaccines over sheep brain vaccines which has hopefully taken place due to the discontinuation of sheep brain vaccine by the government in 2004 [10,21].

1 Haupt W. Rabies- risk of exposure and current trends in prevention of human cases. Vaccine. 1999;17:17429. Medline:10194833 doi:10.1016/S0264-410X(98)00447-2

2 Chatterjee P. India's ongoing war against rabies. Bull World Health Organ. 2009;87:890-1. Medline:20454476 doi:10.2471/BLT.09.021209

3 Dutta JK. Human rabies in India: epidemiological features, management and current methods of prevention. Trop Doct. 1999;29:196-201. Medline:10578630

4 Gongal G, Wright AE. Human rabies in the WHO Southeast Asia region: Forward steps for elimination. Advances in Preventive Medicine 2011;2011: 383870.

5 Ichhpujani RL, Chhabra M, Mittal V, Bhattacharya D, Singh J, Lal S. Knowledge, attitude and practices about animal bites and rabies in general community-a multi-centric study. J Commun Dis. 2006;38:355-61. Medline: 17913213

6 Warrell DA, Warrell MJ. Human rabies: a continuing challenge in the tropical world. Schweiz Med Wochenschr. 1995;125:879-85. Medline:7770748

7 Menezes R. Rabies in India. CMAJ. 2008;178:564-6. Medline:18299543 doi:10.1503/cmaj.071488

8 Sudarshan MK, Madhusudana SN, Mahendra BJ, Rao NS, Ashwath Narayana DH, Abdul Rahman S, et al. Assessing the burden of human rabies in India: results of a national multi-center epidemiological survey. Int J Infect Dis. 2007;11:29-35. Medline:16678463 doi:10.1016/j.ijid.2005.10.007

9 Knobel DL, Cleaveland S, Coleman PG, Févre EM, Meltzer MI, Miranda ME, et al. Re-evaluating the burden of rabies in Africa and Asia. Bull World Health Organ. 2005;83:360-8. Medline:15976877

10 Sudarshan MK, Mahendra BJ, Madhusudana SN, Ashwoath Narayana DH, Rahman A, Rao NS, et al. An epidemiological study of animal bites in India: results of a WHO sponsored national multi-centric rabies survey. J Commun Dis. 2006;38:32-9. Medline:17370688

11 Sudarshan MK, Ashwath Narayana DH. A survey of hospitals managing human rabies cases in India. Indian J Public Health. 2010;54:40-1. Medline:20859051 doi:10.4103/0019-557X.70552 
12 Chhabra M, Ichhpujani RL, Tewari KN, Lal S. Human rabies in Delhi. Indian J Pediatr. 2004;71:217-20. Medline:15080408 doi:10.1007/BF02724273

13 Kumar A, Pal D. Epidemiology of human rabies cases in Kolkata with its application to post prophylaxis. Indian J Anim Res. 2010;44:241-7.

14 von Elm E, Altman DG, Egger M, Pocock SJ, Gřtzsche PC, Vandenbroucke JP. STROBE Initiative. The Strengthening the Reporting of Observational Studies in Epidemiology (STROBE)statement: guidelines for reporting observational studies. Lancet. 2007;370:1453-7. Medline:18064739 doi:10.1016/S0140-6736(07)61602-X

15 Government of India. Area, population, decennial growth rate and density for 2001 and 2011 at a glance for West Bengal and the districts: provisional population totals West Bengal: Government of India, 2011. Available at: http:// www.censusindia.gov.in/2011-prov-results/prov_data_products_wb.html. Accessed: 20 March 2012.

16 Government of India. Census posts. India: Government of India. Available at: http://www.censusindia.gov.in/ default.aspx. Accessed: 20 March 2012.

17 Cleaveland S, Fevre EM. etal. Estimating human rabies mortality in the United Republic of Tanzania from dog bite injuries. Bull World Health Organ. 2002;80:304-10. Medline:12075367

18 Lakhanpal U, Sharma RC. An Epidemiological Study of 177 Cases of Human Rabies. Int J Epidemiol. 1985;14:614-7. Medline:4086148 doi:10.1093/ije/14.4.614

19 Sudarshan MK, Mahendra BJ, Narayan DH. A community survey of dog bites, anti-rabies treatment, rabies and dog population management in Bangalore city. J Commun Dis. 2001;33:245-51. Medline:12561501

20 Garg A, Kumar R, Ingle GK. Knowledge and practices regarding animal bite management and rabies prophylaxis among doctors in Delhi, India. Asia Pac J Public Health. 2012 Feb 15. [Epub ahead of print]. Medline:22345278 doi:10.1177/1010539511436323

21 Wilde H, Khawplod P, Khamoltham T, Hemachudha T, Tepsumethanon V, Lumlerdacha B, et al. Rabies control in South and Southeast Asia. Vaccine. 2005;23:2284-9. Medline:15755612 doi:10.1016/j.vaccine.2005.01.030

\section{Correspondence to:}

Janie M. Baxter

Centre for Population Health Sciences

University of Edinburgh

Teviot Place

Edinburgh EH8 9AG

Scotland, UK

J.M.Baxter@sms.ed.ac.uk 